\title{
Identification and differential expression of serotransferrin and apolipoprotein A-I in the plasma of HIV-1 patients treated with first-line antiretroviral therapy
}

Sushanta Kumar Barik

Keshar Kunja Mohanty ( $\sim$ keshar63@yahoo.com )

National JALMA Institute for Leprsoy and Other Mycobacterial Diseases https://orcid.org/0000-00017527-4864

Ashok Kumar Mohanty

Preeti Rawat

G Gopal

Deepa Bisht

Shripad A Patil

Rananjay Singh

Devesh Sharma

Srikanth Prasad Tripathy

Rekha Tandon

Tej Pal Singh

Srikanta Jena

Research

Keywords: HIV, AIDS, First line ART, Drug resistant, Drug respondent

Posted Date: June 15th, 2020

DOI: https://doi.org/10.21203/rs.3.rs-33825/v1

License: (c) (i) This work is licensed under a Creative Commons Attribution 4.0 International License.

Read Full License 


\section{Abstract \\ Background}

As plasma proteins were involved in drug metabolism, the aim of the study was to identify and characterize the plasma proteins of the drug resistant and drug respondent groups of HIV-1 infected first line ART patients with $>6$ years in therapy.

\section{Methods}

Plasma proteomics analysis of the four drug-resistant (treatment failure) and four drug respondent (treatment responder) groups were conducted. High abundant plasma proteins like albumin and globulin were depleted from plasma through Aurum serum mini kit (Bio-Rad, USA). Plasma proteins were resolved using two-dimensional gel electrophoresis on IPG strips, $\mathrm{pH}$ range of 3-10. Eight protein spots were selected in the gel based on the density of staining which was common in the drug resistant and drug respondent groups separately. The fold change of each spot was calculated using image-J. Each protein spot was identified using the matrix assisted laser desorption/ionization-time of flight/time of flight (MALDI-TOF/TOF) after tryptic digestion. Peptide peaks were identified through flex analysis version 3.3, and a search against a protein database using the internal mascot search engine. Gene ontology study was completed through STRING v.11 and Panther 15.0.

\section{Results}

Out of eight spots from 2D gel of drug respondent and drug resistant samples analyzed by MALDI TOF/TOF, two proteins were found to have significant score $(i ; e>56)$ after Flex analysis. These two proteins were identified to be apolipoproteinA1 and Serotransferrin. The fold change expression of these two proteins were analyzed in drug resistant and drug respondent group. ApolipoproteinA1 and serotransferrin were observed to be expressed 1.76 and 1.13-fold more respectively in drug respondent group compared to drug resistant group. The gene ontology analysis revealed the involvement of these two proteins in various important physiological processes.

\section{Conclusion}

Apolipoprotein A-I and serotransferrin were found to be expressed more in drug respondent group compared to drug resistant group.

\section{Introduction}

Human immunodeficiency virus (HIV) is the main cause of acquired immunodeficiency syndrome (AIDS) [1]. Innate and adaptive factors in human plasma regulate the activation of the HIV-1 genome after 
infection [2]. HIV drug resistance is a major problem and a threat in epidemic control [3]. Even there is no specific option to cure AIDS [4]. Clinically significant interactions between the drug and plasma proteins were observed. The pharmacological activity of anti-retroviral (ARV) drugs is dependent on unbound drug entering cells that harbour the human immunodeficiency virus (HIV). There has been concern that changes in protein binding could impact on antiviral activity and management. The study of pharmacological activity of antiretroviral drugs in HIV patients is very important. Changes in protein binding could impact antiviral activity in the host [5]. Plasma protein binding to the drugs and its effective modulation in drug metabolism helps in drug discovery and development of new drug therapy [6].

The matrix-assisted laser desorption/ionization time-of-flight/time-of-flight (MALDI-TOF/TOF) MS analyses of fractioned human serum or plasma samples were carried out earlier [7]. Human saliva or serum proteins were identified through MALDI-TOF/MS for biomarker discovery [8-9]. Plasma proteins are the main components of the human plasma proteome. It is very crucial to identify and delineate the proteins in each individual. In a disease population, the gene or protein diversity study aid in clinical biomarker discovery. The protein diversity related to the disease can be identified and evaluated easily in a population [10]. Therefore, we identified the plasma proteins in drug resistant (treatment failure) and drug respondent (treatment responder) groups of HIV-1 patients who were treated with first-line ART over six years.

\section{Materials And Methods Study subjects}

The study included eight HIV-1 patients in first-line ART enrolled from the period 2009 to 2016 at ART center, Sarojini Naidu Medical College, Agra, India. The CD4 counts of each patient were $<350 \mathrm{cubic} / \mathrm{mm}$ at the time of blood sample collection. The clinical and sociodemographic features were collected through patient information leaflets [11]. Four male and four female patients of 28-45 years were included in this plasma proteomics study. $10 \mathrm{~mL}$ blood sample was collected from each patient. Plasma was isolated for viral load and stored at $-80^{\circ} \mathrm{C}$ for genotyping and proteomic analysis. Four patients had viral load > 1000 copies/ml (drug resistant) and another four patients had viral load $<1000$ copies $/ \mathrm{ml}$ (drug respondent).

\section{Viral Load}

Viral load of eight samples were completed using the Abbott automated m2000rt instrument stationed at National Institute for Research in Tuberculosis, Chennai, India. Four samples had a high viral load(RNA > 1000 copies $/ \mathrm{mL}$ ) and another four had $<62$ RNA copies/ $\mathrm{mL}$ to target not detected levels $(<40$ copies $/ \mathrm{mL})$.

\section{Genotyping}


The four higher viral load patients were considered for genotyping by the WHO dried blood spot protocol 2010. (WHO, 2010) [12]. The details of PCR and primer conditions are given in supplementary file-1.

\section{Reagents And Samples}

IPG strips(7 cm, pH 3-10)(Biorad, USA), sample rehydration buffer (Biorad,USA), acetonitrile (Sigma, USA), LC MS grade water, ammonium bicarbonate (Biorad, USA), Dithiothritol (Sigma, USA,iodo acetamide (Sigma, USA), formic acid (Sigma, USA), acetonitrile (Sigma, USA), trypsin (Promega), zip tip with C18 material (Millipore, Germany). A60 $\mu$ l plasma sample was taken for depletion of highly abundant proteins like immunoglobulins and albumins (Biorad mini kit, USA). The 10\% SDS-PAGE was performed with depleted samples in figure -1 .

\section{2-dimensional Gel Electrophoresis And Tryptic Digestion}

Briefly, a $120 \mu \mathrm{g}$ of protein sample was prepared in sample rehydration buffer. Passive rehydration of the protein was conducted for $22 \mathrm{hrs}$, followed by active rehydration in 8 steps such as $1.50 \mathrm{~V}-2 \mathrm{hrs}$-slow, $2.250 \mathrm{~V}-0.15 \mathrm{hrs}-\mathrm{slow}, 3.1000 \mathrm{~V}-0.30 \mathrm{hrs}-\mathrm{slow}, 4.1500 \mathrm{~V}-0.30 \mathrm{hrs}-\mathrm{slow}, 5.2500 \mathrm{~V}-0.30 \mathrm{hrs}-\mathrm{rapid}, 6.4000-3 \mathrm{hrs}-$ rapid 7.4000-4hrs-rapid, 8.500-5hrs-rapid. First dimensional gel electrophoresis was performed on a horizontal IEF apparatus (Biorad, USA) and second dimensional gel electrophoresis was performed using $10 \%$ SDS-PAGE. The SDS-PAGE was stained in 0.2\% Coomassie brilliant blue R-250.The 2-D gel electrophoresis is given in the figure-2. The magnified images of each spots are given in the figure-3. Tryptic digestion was performed by the following protocol [13].A Zip tip with $\mathrm{C} 18$ material was used for desalting of peptides. The desalted peptides were vacuum-dried.

\section{MALDI-TOF-TOF/MS Analysis}

Vacuum dried peptides were suspended in $10 \mu \mathrm{l}$ of a $50 \%$ acetonitrile/ $0.1 \%$ formic acid solution. One microliter of samples and one microliter matrix consisting of a saturated solution of a-cyano-4hydroxycinnamic acid prepared in $50 \%$ acetonitrile/ $0.1 \%$ formic acid were spotted onto the MALDI sample target plate of the Brucker Daltonics work station. 1000 shots and 5000 shots were taken for each sample using MALDI-TOF-TOF /MS (Bruker Daltonics, USA) and peptide peaks were analyzed using flex analysis version 3.3. Proteins were identified in the Mascot search engine. Protein score greater than 56 with $p$ value $<0.05$ are considered as significant score.

\section{Results}

In this study, the patients were classified in two groups based on their drug resistance/viral copy numbers as drug resistant and drug respondent. Drug resistant group is defined as the patients who were having a higher viral load (copy number at least $>1000$ copies/ml, low CD 4 counts ( $<350$ cubic/mm) and NRTls 
and NNRTIs associated mutations in the reverse transcriptase gene of HIV-1.The drug resistant group considered as treatment failure. In the same way, the drug respondent group is defined as the patients were having low CD 4 counts ( 350 cubic/mm), low viral load copies ( $<62$ copies $/ \mathrm{ml}$ to target not detected level) and had no NRTIs and NNRT Is associated mutations in the reverse transcriptase gene of HIV-1. The drug respondent group considered as treatment success or virological success.

\section{Identification Of Differentially Expressed Proteins By MALDI-TOF/TOF}

Eight protein spots were identified in the gel based on the density of staining which was common in the drug resistant and drug respondent groups separately. The fold change of each spot was calculated using image-J [14]. The average density of individual spot of 4 drug respondent and drug resistant samples were measured. Then the ratio of the average density of individual spot of the drug respondent to the drug resistant samples was calculated. The ratio was represented as fold change expression.

Eight common spots of drug respondent and drug resistant groups were taken for identification by MALDI-TOF/TOF. These spots were identified to be neuropeptide -B, colied-coil domain containing protein 104 , keratin type-II cytoskeletal-I, serotransferrin, Apolipoprotein-AI, WD repeat containing protein, Ig kappa chain -V-III region, $\mathrm{pH}$ interacting protein. However, two proteins serotransferrin and apolipoprotein A-I were having significant (score $>56$ ) through the MASCOT search engine. The serotransferrin of the respondent group was 1.13 fold change expression in comparison to the resistant group. The apolipoprotein A-I of drug respondent group was $1.76 \mathrm{fold}$ change expression compared to the resistant group. The mascot scores histograms are given in Fig. 4 and Fig. 5 for serotransferrin and apolipoproteinA1 respectively.

\section{Gene Ontology Study}

The gene ontology of apolipoprotein -Al and serotransferrin was identified using STRING V.11 [15]. The biological process, cellular components and reactome pathways were analysed by string 11.0. The molecular function of the apolipoprotein-A1 was analyzed by panther -gene analyst 15.0 [16]. A protein network link was found in between apolipoprotein-A1 and serotransferrin. A detailed description of gene ontology analysis is given in the supplementary file-2.

\section{Viral Load And Mutations In Hiv Drug Resistant Group}

The four drug resistant patients had a viral load of $30694 \mathrm{copies} / \mathrm{ml}, 103158 \mathrm{copies} / \mathrm{ml}, 6266 \mathrm{copies} / \mathrm{ml}$, 2950 copies/ml in each patient respectively. The nucleoside reverse transcriptase inhibitors (NRTIs) and non-nucleoside reverse transcriptase inhibitors (NNRTIs) drug resistance mutations of the four patients were analyzed using the HIV drug resistance database, Stanford University, USA. The NRTI mutations 
M184V, 230L, K65R, Y115F,and NNRTI mutations G190A and V106M were detected in four drug resistant patients.

\section{Discussion}

Human plasma proteins have proven to be essential components of the blood and the study of these proteins is helpful to find out the function of the proteins involved in metabolism. The study of these proteins will be helpful for the development of diagnostic, prognostic or therapeutic markers in a disease. The pathogenicity of HIV is a global health concern. The study of protein-protein interactions, and protein drug interaction in HIV patients is crucial during the therapy. Some of the important proteins were earlier characterized in HIV patients.

The APOA1 levels were measured in HIV-1 infected patients who are on nevirapine therapy. It was found that women had higher APOA1 levels than men. Apolipoprotein Al increased the level of sulfotransferase family 2B member 1 gene activity and the Apolipoprotein Al synthesis was increased by Nevirapine. ApoA1 different expression levels by aspartate amino transferase and alanine aminotransferase was associated with sex dimorphic mechanism leading to Nevirapine induced hepatotoxicity in HIV-1 patients [17]. Nevirapine increased the level of APO-Al in HIV-1 infected patients [18]. Apo-Al was associated with Apolipoprotein -Al binding protein to inhibit HIV replication [19]. In this study, lower level expression of APO-Al protein was observed in the drug resistant group as compared with the drug respondent group. Lower level expression of APO-Al might be the cause of high viremia and lower CD4 count in the drug resistant group of patients.

Serotransferrins are iron-binding proteins that have antimicrobial properties[20]. Higher iron levels in serum was associated with HIV replication and increased HIV infection [21]. Iron status was not an indication of disease severity in HIV-infected pregnant women in Malwai [22], but another finding was just reverse on iron overload was the severity in adults with HIV-1 infected Caucasian population[23]. In our study findings, the level of serotransferrin was higher in the drug respondent group than in the drug resistant group. Further studies will be required to address the iron uptake in both groups.

\section{Conclusion}

Apolipoprotein A-I and serotransferrin were found to be expressed more in drug respondent group compared to drug resistant group. This finding could further be explored to find out the mechanism and exploration of biomarkers in drug resistant group.

\section{Abbreviations}

HIV

Human immune-deficiency virus

AIDS 
Acquired immune-deficiency syndrome

MALDI-TOF-TOF

Matrix assisted laser desorption/ionization -time of flight/time of flight

IPG

Immobilized $\mathrm{pH}$ gradient

IEF

Iso electro focusing

SDS-PAGE

Sodium dodecyl sulfate -polyacrylamide gel electrophoresis

NRTI

Nucleoside reverse transcriptase inhibitors

\section{Declarations}

Ethics Approval and Consent to Participate: The details of the research plan of the study were informed to the patients in Hindi language in written form. Then the written informed consent was obtained from the study participants. This study was approved by the ethics committee.

\section{Consent for publication}

All authors have assigned this article for publication to this journal

Availability of data and materials: Yes, PR and RT gene sequences at NCBI.

\section{Competing interest}

"No competing financial interests exist."

\section{Funding}

Indian Council of Medical Research, Govt. of India has funded the senior research fellowship of Sushanta Kumar Barik and contingencies grant. The sanction file number of the project: 80/990/2015-ECD-I.

\section{Acknowledgements}

Indian Council of Medical Research, Govt. of India is acknowledged for providing the ICMR-SRFship to Mr Sushanta Kumar Barik.

\section{Gene Bank accession number}

All submitted gene bank accession numbers of the drug resistant group are MG788713, MG788728, MG788738, MG788748.

\section{References}


1. Gallo RC, Montagnier L. The discovery of HIV as the cause of AIDS. New England Journal of Medicine. 2003 Dec 11;349(24):2283-5.

2. Shah S, Nonnemacher MR, Pirrone V, Wigdahl B. Innate and adaptive factors regulating human immunodeficiency virus type 1 genomic activation. Journal of Neuroimmune Pharmacology. 2010 Sep 1;5(3):278 - 93.

3. Beyrer C, Pozniak A. HIV drug resistance-an emerging threat to epidemic control. New England Journal of Medicine. 2017 Oct 26;377(17):1605-7.

4. Sankaranantham M. HIV-Is a cure possible? Indian journal of sexually transmitted diseases AIDS. 2019 Jan;40(1):1.

5. Boffito M, Back DJ, Blaschke TF, Rowland M, Bertz RJ, Gerber JG, Miller V. Protein binding in antiretroviral therapies. AIDS research and human retroviruses. 2003 Sep 1;19(9):825 - 35.

6. Bohnert T, Gan LS. Plasma protein binding: from discovery to development. Journal of pharmaceutical sciences. 2013 Sep 1;102(9):2953-94.

7. Leung SM, Pitts RL. A novel approach using MALDI-TOF/TOF mass spectrometry and prestructured sample supports (AnchorChip Technology) for proteomic profiling and protein identification. InTissue Proteomics 2008 (pp. 57-70).

8. Vitorino R, Lobo MJ, Ferrer-Correira AJ, Dubin JR, Tomer KB, Domingues PM, Amado FM. Identification of human whole saliva protein components using proteomics. Proteomics. 2004 Apr;4(4):1109-15.

9. Riaz S. Study of protein biomarkers of diabetes mellitus type 2 and therapy with vitamin B1. Journal of diabetes research. 2015;2015.

10. Nedelkov D, Kiernan UA, Niederkofler EE, Tubbs KA, Nelson RW. Investigating diversity in human plasma proteins. Proceedings of the National Academy of Sciences. 2005 Aug 2;102(31):10852-7.

11. Barik SK, Tomar S, Tandon R, Mohanty KK, Joshi B. Practical Challenges in Implementing a Simplified Leaflet for HIV Patients in Resource Poor Settings: The Practice towards Public Health. J Gen Pract. 2018;6(347):2.

12. World Health Organization. WHO manual for HIV drug resistance testing using dried blood spot specimens, March, 2010.

13. Bathla S, Rawat P, Baithalu R, Yadav ML, Naru J, Tiwari A, Kumar S, Balhara AK, Singh S, Chaudhary $S$, Kumar R. Profiling of urinary proteins in Karan Fries cows reveals more than 1550 proteins. Journal of proteomics. 2015 Sep 8;127:193-201.

14. NIH Image to ImageJ. 25 years of image analysis Caroline A Schneider, Wayne S Rasband \& Kevin W Eliceiri.Nature Methods volume 9, pages 671-675(2012).

15. Szklarczyk D, Gable AL, Lyon D, Junge A, Wyder S, Huerta-Cepas J, Simonovic M, Doncheva NT, Morris JH, Bork P, Jensen LJ. STRING v11: protein-protein association networks with increased coverage, supporting functional discovery in genome-wide experimental datasets. Nucleic acids research. 2019 Jan 8;47(D1):D607-13. 
16. Mi H, Muruganujan A, Ebert D, Huang X, Thomas PD. PANTHER version 14: more genomes, a new PANTHER GO-slim and improvements in enrichment analysis tools. Nucleic acids research. 2019 Jan 8;47(D1):D419-26.

17. Marinho A, Dias C, Antunes A, Caixas U, Branco T, Marques M, Monteiro E, Pereira S. Sex differences in apolipoprotein A1 and nevirapine-induced toxicity. J Int AIDS Soc. 2014 Nov;17:19575.

18. Franssen R, Sankatsing RR, Hassink E, Hutten B, Ackermans MT, Brinkman K, Oesterholt R, ArenasPinto A, Storfer SP, Kastelein JJ, Sauerwein HP. Nevirapine increases high-density lipoprotein cholesterol concentration by stimulation of apolipoprotein Al production. Arteriosclerosis, thrombosis, and vascular biology. 2009 Sep 1;29(9):1336 - 41.14 Nov;17:19575.

19. Dubrovsky L, Ward A, Choi SH, Pushkarsky T, Brichacek B, Vanpouille C, Adzhubei AA, Mukhamedova $\mathrm{N}$, Sviridov D, Margolis L, Jones RB. Inhibition of HIV replication by apolipoprotein Al binding protein targeting the lipid rafts. Mbio. 2020 Feb 25;11(1).

20. Satta N, Pagano S, Montecucco F, Gencer B, Aubert V, Barth J, Battegay M, Bernasconi E, Böni J, Bucher HC, Burton-Jeangros $\mathrm{C}$. Anti-apolipoprotein A-1 autoantibodies are associated with immunodeficiency and systemic inflammation in HIV patients. Journal of Infection. 2018 Feb 1;76(2):186 - 95.

21. Chang HC, Bayeva M, Taiwo B, Palella FJ Jr, Hope TJ, Ardehali H. High cellular iron levels are associated with increased HIV infection and replication. AIDS research and human retroviruses. 2015 Mar 1;31(3):305 - 12.

22. Semba RD, Taha TE, Kumwenda N, Mtimavalye L, Broadhead R, Miotti PG, Chiphangwi JD. Iron status and indicators of human immunodeficiency virus disease severity among pregnant women in Malawi. Clinical Infectious Diseases. 2001 May 15;32(10):1496-9.

23. Delanghe JR, Langlois MR, Boelaert JR, Van Acker J, Van Wanzeele F, van der Groen G, Hemmer R, Verhofstede C, De Buyzere M, De Bacquer D, Arendt V. Haptoglobin polymorphism, iron metabolism and mortality in HIV infection. Aids. 1998 Sep 1;12(9):1027-32.

\section{Figures}




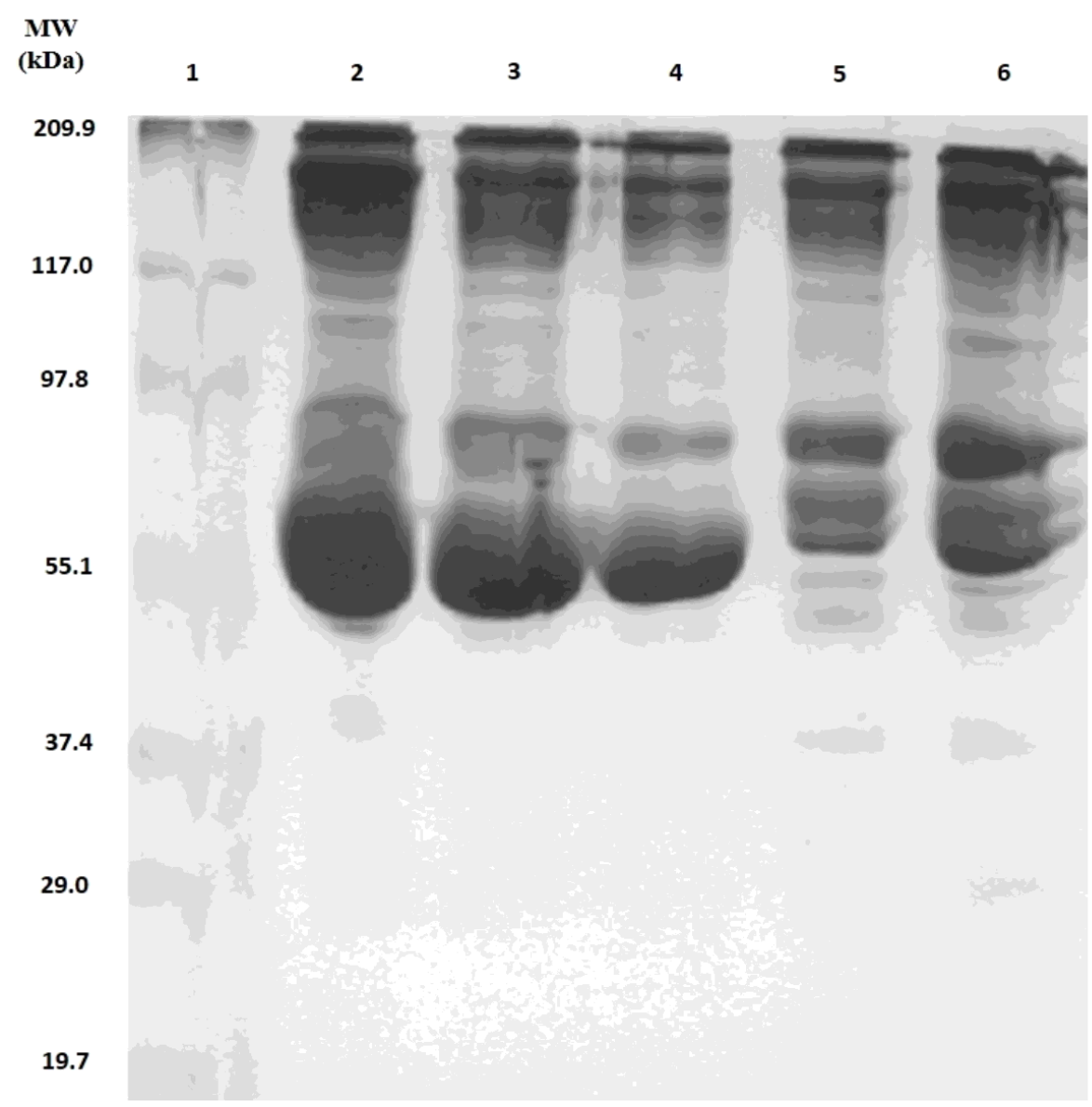

Fig. 1: SDS-PAGE of plasma proteins extracted from HIV-1 infected human and their purification by Aurum serum kit (Bio-Rad, USA). Lane 1: Proteins marker; Lane 2, 3, 4: Before purification; Lane 5, 6: After purification

Figure 1

SDS-PAGE of plasma proteins extracted from HIV-1 infected human and their purification by Aurum serum kit (Bio-Rad, USA). Lane 1: Proteins marker; Lane 2, 3, 4: Before purification; Lane 5, 6: After purification 


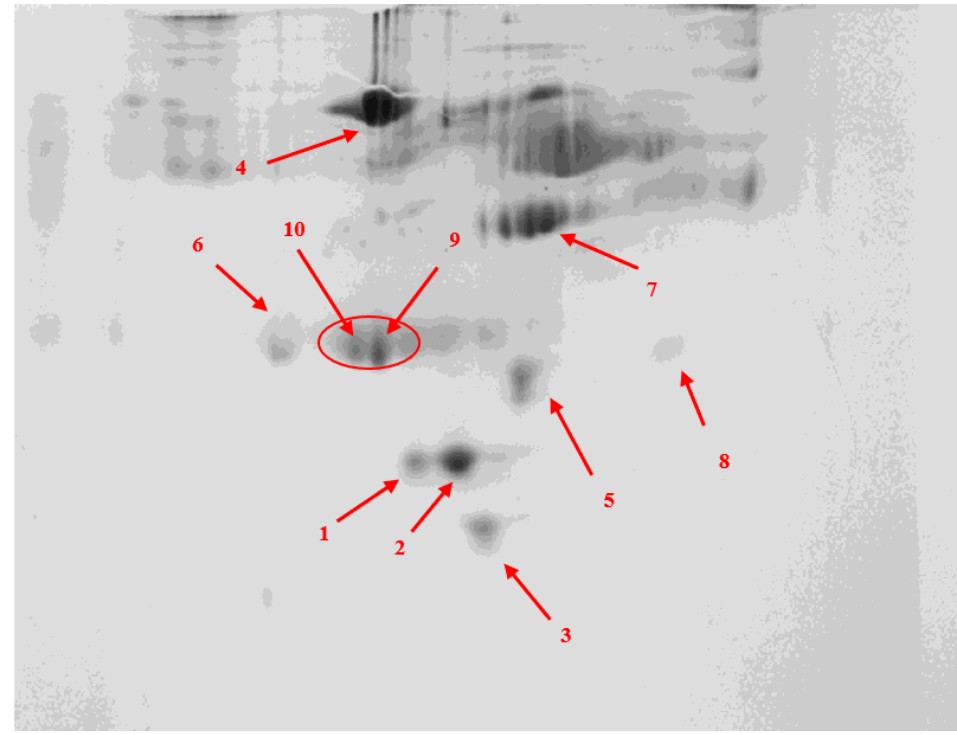

$\mathbf{A}$

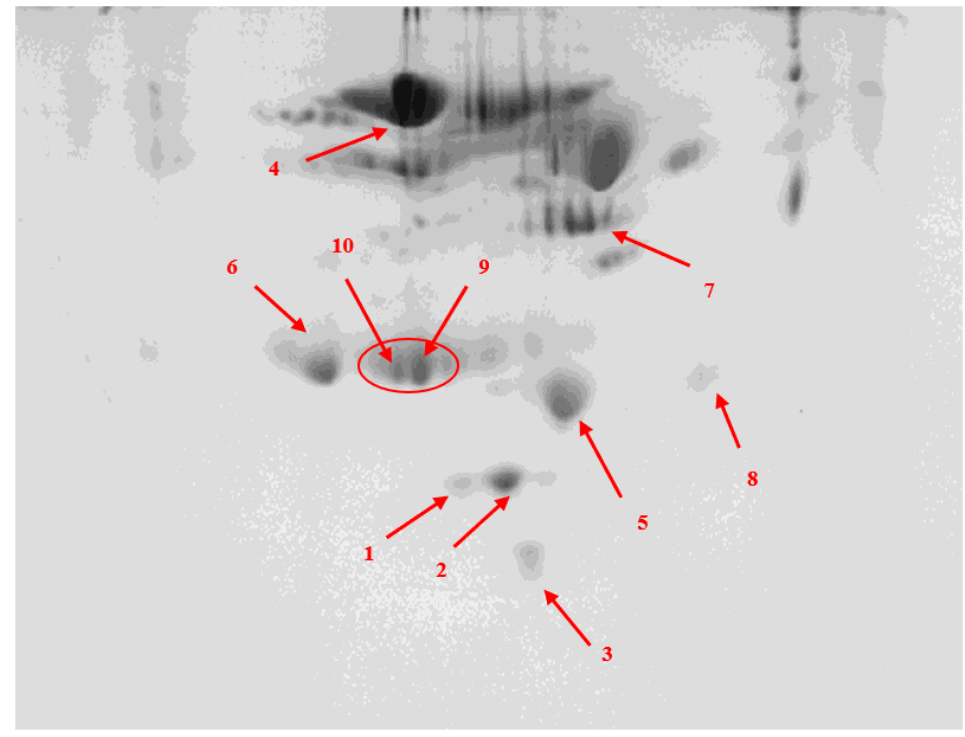

Fig. 2: 2D gels electrophoresis of purified proteins from human plasma samples of HIV-1 patient.

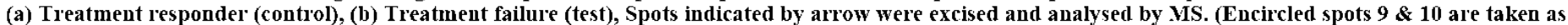
internal control)

\section{Figure 2}

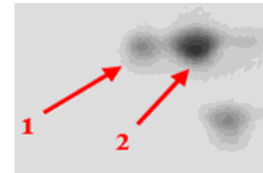

(a)

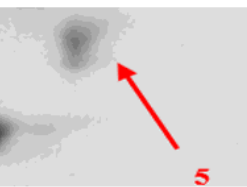

(a)

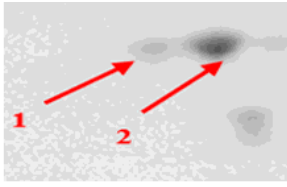

(b)

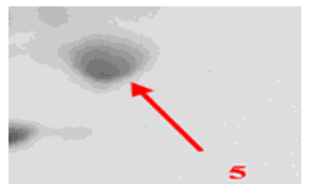

(b)

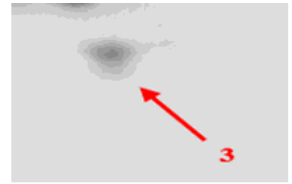

(a)

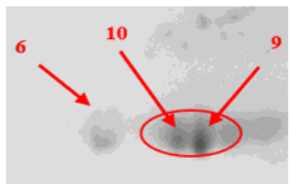

(a)

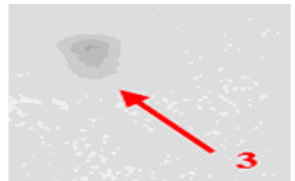

(b)

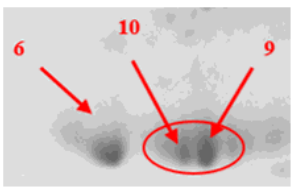

(b)

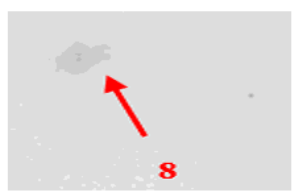

(b)

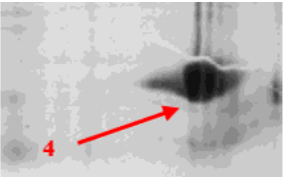

(a)

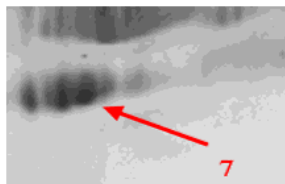

(a)

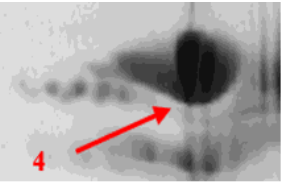

(b)

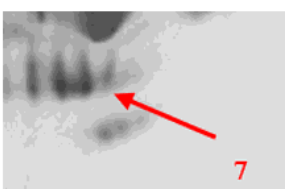

(b)

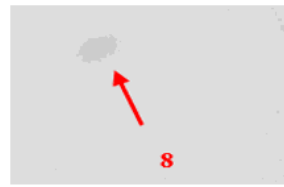

(a)

Fig.3: Magnified regions of 2D gels showing expression of protein (a) Treatment responder (control), (b) Treatment failure (test)

\section{Figure 3}




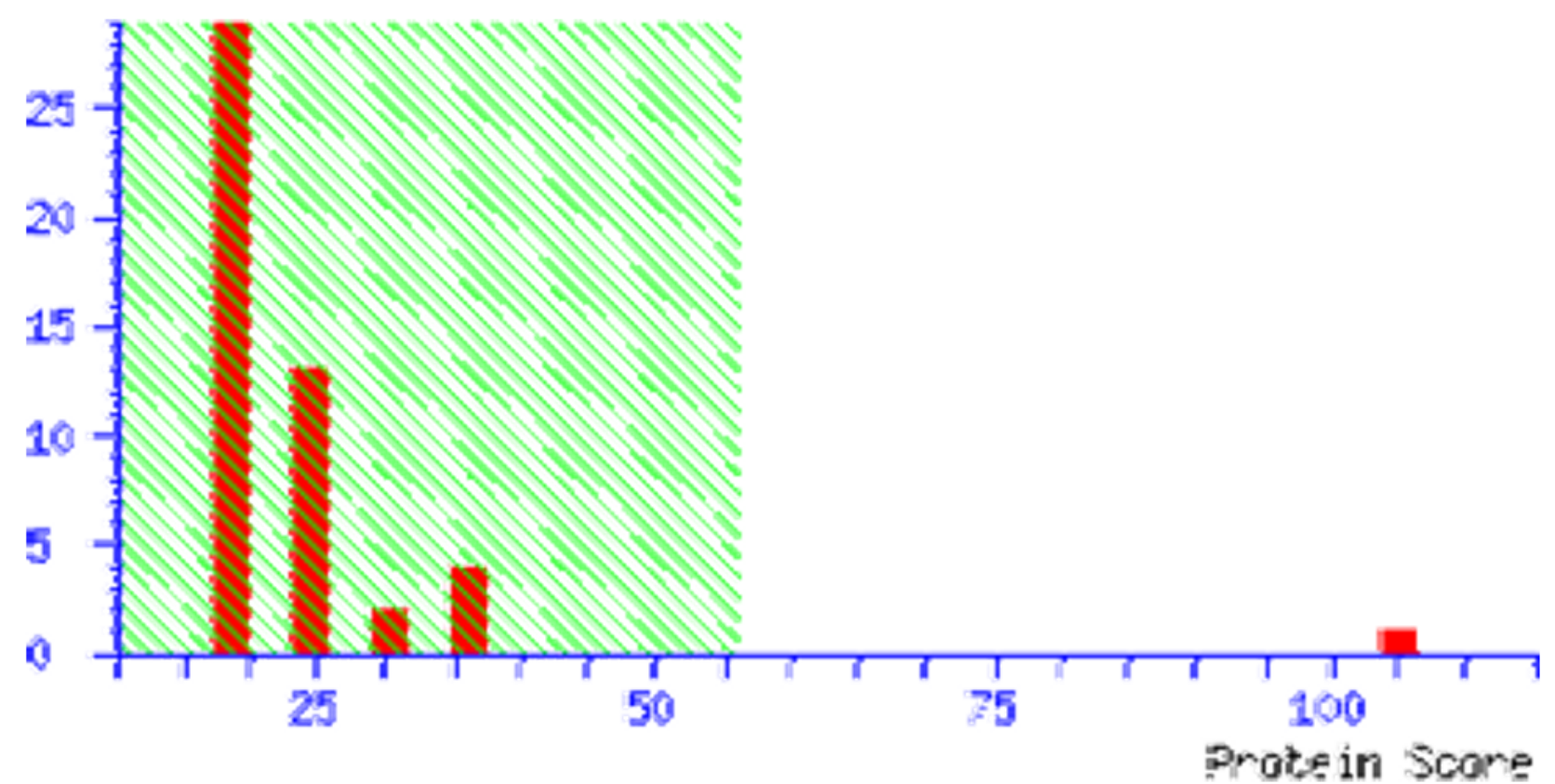

Score 105 for Human serotransferrin

Figure 4

Mascot Score Histogram for serotransferrin. The protein score is $-10 * \log (P)$, where $P$ is the probability that the observed match is a random event. Protein scores greater than 56 were significant $(p<0$

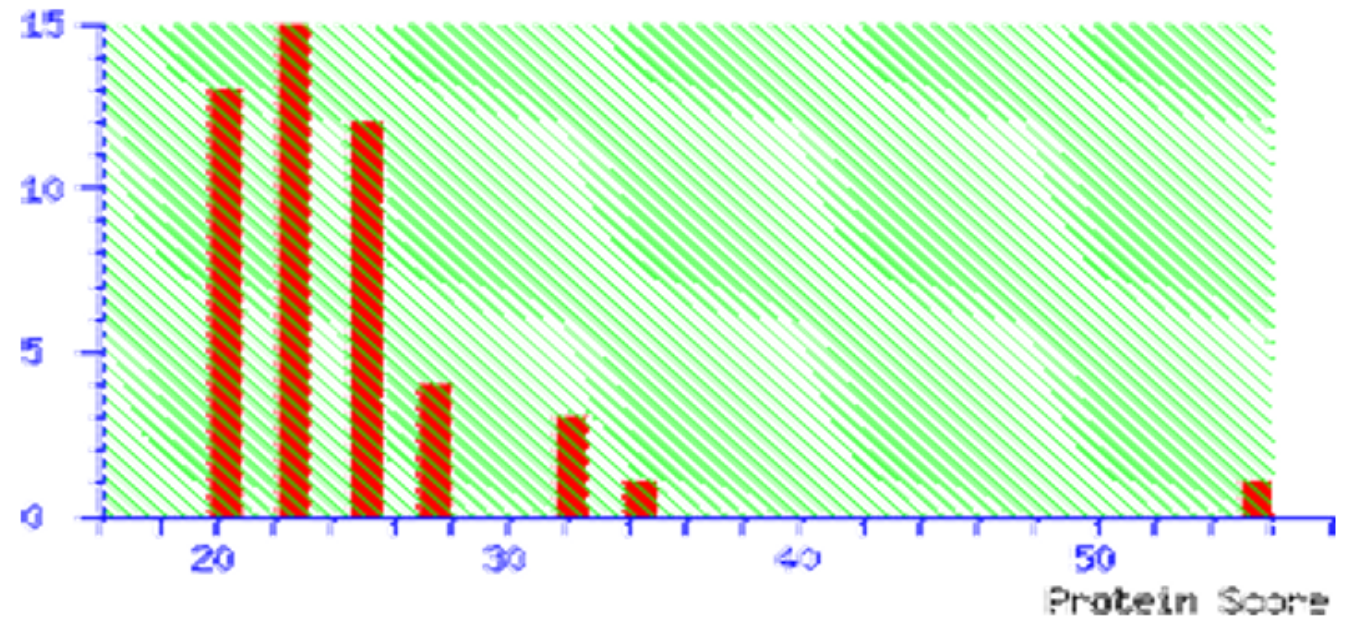

Score 56 for human apolipoprotein A-I (APOA1)

Figure 5 
Mascot Score Histogram of apolipoprotein A-I. The protein score is $-10^{*} \log (P)$, where $P$ is the probability that the observed match is a random event. Protein scores greater than 56 were significant $(p<0.05)$.

\section{Supplementary Files}

This is a list of supplementary files associated with this preprint. Click to download.

- Supplementaryfile2geneontology.docx

- Supplementaryfile1primersandpcrconditions.docx 